\title{
Coupled fixed point theorems in cone metric spaces with a $c$-distance and applications
}

\author{
Erdal Karapinar ${ }^{1}$, Poom Kumam² ${ }^{2 *}$ and Wutiphol Sintunavarat ${ }^{2 *}$
}

\section{"Correspondence:}

poom.kum@kmutt.ac.th:

poom_teun@hotmail.com

${ }^{2}$ Department of Mathematics,

Faculty of Science, King Mongkut's University of Technology Thonburi

(KMUTT), Bangkok, 10140, Thailand

Full list of author information is

available at the end of the article

\begin{abstract}
In this paper, we extend the very recent result of Sintunavarat et al. in the paper 'Coupled fixed point theorems for weak contraction mapping under F-invariant set' (Abstr. Appl. Anal. 2012:324874, 2012). In particular, we give an example of a nonlinear contraction mapping for which our result successfully detects a coupled fixed point in contrast to the result of Sintunavarat et al., which is not applied to show the existence of a coupled fixed point. As a consequence, the main results in this paper extend and unify many results in the topic of coupled fixed points including the results of Sintunavarat et al. Also, some applications of the main results are given. MSC: $54 \mathrm{H} 25 ; 47 \mathrm{H} 10$
\end{abstract}

Keywords: coupled fixed point; F-invariant set; partially ordered cone metric space; c-distance

\section{Introduction}

Let $X$ be an arbitrary nonempty set and $f: X \rightarrow X$ be a mapping. A fixed point for $f$ is a point $x \in X$ such that $f x=x$. Many useful mathematical facts can be expressed by assertions that say that certain mappings have fixed points. Fixed point theory, one of the very active research areas in mathematics as well as quantitative sciences, focuses on maps and abstract spaces for which one can assure the existence and/or uniqueness of fixed points when they are put together. For example, fixed point theorems are vital for the existence and uniqueness of differential equations, matrix equations, and integral equations (see, e.g., $[1,2])$. Moreover, it has applications in many fields such as chemistry, biology, statistics, economics, computer science and engineering (see, e.g., [3-6]). For example, fixed point results are incredibly useful when it comes to proving the existence of various types of Nash equilibria (see, e.g., [3]) in economics.

The classical contraction mapping principle of Banach is one of the most powerful theorems in fixed point theory because of its simplicity and usefulness. So, it has become a very popular tool for solving many problems in many branches of mathematical analysis and also in many other fields. Refer to [7-17] and references mentioned therein for certain extensions of this principle. In 2004, the Banach contraction principle was extended to metric spaces endowed with a partial ordering by Ran and Reurings [18]. They also gave some applications of their results to matrix equations. Afterwards, Nieto and RodríguezLópez [19] extended the results of Ran and Reurings for nondecreasing mappings and studied the existence and uniqueness of solutions for a first-order ordinary differential equation with periodic boundary conditions.

() 2012 Karapinar et al.: licensee Springer. This is an Open Access article distributed under the terms of the Creative Commons Attribution License (http://creativecommons.org/licenses/by/2.0), which permits unrestricted use, distribution, and reproduction in any medium, provided the original work is properly cited. 
In 2006, Bhaskar and Lakshmikantham [20] introduced the concept of a mixed monotone property for the first time and gave their classical coupled fixed point theorems for mappings which satisfy the mixed monotone property. They also produced some applications in the existence and uniqueness of solutions for the periodic boundary value problem

$$
\begin{aligned}
& u^{\prime}(t)=f(t, u(t)), \quad t \in[0, T], \\
& u(0)=u(T),
\end{aligned}
$$

where the function $f$ satisfies certain conditions. Afterwards, Harjani et al. [21] and Luong and Thuan $[22,23]$ studied the existence and uniqueness of solutions of nonlinear integral equations as an application of coupled fixed points. Recently, Caballero et al. [24] have investigated the existence and uniqueness of positive solutions for the following singular fractional boundary value problem:

$$
\begin{aligned}
& D_{0^{+}}^{\alpha} u(t)+f(t, u(t))=0, \quad 0<t<1, \\
& u(0)=u(1)=0,
\end{aligned}
$$

where $\alpha \in \mathbb{R}$ such that $1<\alpha \leq 2$. Here $D_{0^{+}}^{\alpha}$ is the standard Riemann-Liouville differentiation. The function $f:(0,1] \times[0, \infty) \rightarrow[0, \infty)$ has the property $\lim _{t \rightarrow 0^{+}} f(t, \cdot)=\infty$ for all $t \in(0,1]$ (i.e., $f$ is singular at $t=0$ ). Very recently, motivated by the work of Caballero et al. [24], Jleli and Samet [25] discussed the existence and uniqueness of a positive solution for the singular nonlinear fractional differential equation boundary value problem

$$
\begin{aligned}
& D_{0^{+}}^{\alpha} u(t)=f(t, u(t), u(t)), \quad 0<t<1, \\
& u(a)=u^{\prime}(b)=0, \quad a, b \in\{0,1\},
\end{aligned}
$$

where $\alpha \in \mathbb{R}$ such that $3<\alpha \leq 4$. Above $D_{0^{+}}^{\alpha}$ is also the Riemann-Liouville fractional derivative. The function $f:(0,1] \times[0, \infty) \times[0, \infty) \rightarrow[0, \infty)$ is continuous, $\lim _{t \rightarrow 0^{+}} f(t, \cdot, \cdot)=\infty$ for all $t \in(0,1]$, and nondecreasing with respect to the first component, decreasing with respect to its second and third components.

Because of their important roles in the study of the existence and uniqueness of solutions of the periodic boundary value problems, nonlinear integral equations and the existence and uniqueness of positive solutions for the singular nonlinear fractional differential equations with boundary value, discussions on coupled fixed point theorems are of interest to many scientists. A considerable number of articles have been dedicated to the improvement and generalization of this topic (see [26-33] and references therein).

On the other hand, Huang and Zhang [34] reintroduced the notion of cone metric spaces and established fixed point theorems for mappings in such spaces. In 2011, Cho et al. [35] introduced a new concept of a $c$-distance, a cone version of a $w$-distance of Kada et al. [36], in cone metric spaces and proved some fixed point theorems in partially ordered cone metric spaces using the notion of a $c$-distance. Afterwards, Sintunavarat et al. [37] (see also [38]) established fixed point theorems for some type of generalization of contraction mappings by using this concept. 
Recently, Cho et al. [39] established new coupled fixed point theorems under contraction mappings by using the concept of the mixed monotone property and $c$-distance in partially ordered cone metric spaces as follows.

Theorem 1.1 ([39]) Let $(X, \sqsubseteq)$ be a partially ordered set and suppose that $(X, d)$ is a complete cone metric space. Let $q$ be a c-distance on $X$ and $F: X \times X \rightarrow X$ be a continuous function having the mixed monotone property such that

$$
q\left(F(x, y), F\left(x^{*}, y^{*}\right)\right) \leq \frac{k}{2}\left(q\left(x, x^{*}\right)+q\left(y, y^{*}\right)\right)
$$

for some $k \in[0,1)$ and all $x, y, x^{*}, y^{*} \in X$ with

$$
\left(x \sqsubseteq x^{*}\right) \wedge\left(y \sqsupseteq y^{*}\right) \quad \text { or } \quad\left(x \sqsupseteq x^{*}\right) \wedge\left(y \sqsubseteq y^{*}\right) .
$$

If there exist $x_{0}, y_{0} \in X$ such that

$$
x_{0} \sqsubseteq F\left(x_{0}, y_{0}\right) \text { and } F\left(y_{0}, x_{0}\right) \sqsubseteq y_{0} \text {, }
$$

then $F$ has a coupled fixed point $(u, v)$. Moreover, we have $q(v, v)=\theta$ and $q(u, u)=\theta$.

Theorem 1.2 ([39]) In addition to the hypotheses of Theorem 1.1, suppose that any two elements $x$ and $y$ in $X$ are comparable. Then the coupled fixed point has the form $(u, u)$, where $u \in X$.

Theorem 1.3 ([39]) Let $(X$, ) be a partially ordered set and suppose that $(X, d)$ is a complete cone metric space. Let $q$ be a c-distance on $X$ and $F: X \times X \rightarrow X$ be a function having the mixed monotone property such that

$$
q\left(F(x, y), F\left(x^{*}, y^{*}\right)\right) \preceq \frac{k}{4}\left(q\left(x, x^{*}\right)+q\left(y, y^{*}\right)\right)
$$

for some $k \in(0,1)$ and all $x, y, x^{*}, y^{*} \in X$ with

$$
\left(x \sqsubseteq x^{*}\right) \wedge\left(y \sqsupseteq y^{*}\right) \quad \text { or } \quad\left(x \sqsupseteq x^{*}\right) \wedge\left(y \sqsubseteq y^{*}\right) .
$$

Also, suppose that $X$ has the following properties:

(a) if $\left(x_{n}\right)$ is a non-decreasing sequence in $X$ with $x_{n} \rightarrow x$, then $x_{n} \sqsubseteq x$ for all $n \in \mathbb{N}$;

(b) if $\left(x_{n}\right)$ is a non-increasing sequence in $X$ with $x_{n} \rightarrow x$, then $x \sqsubseteq x_{n}$ for all $n \in \mathbb{N}$.

Assume there exist $x_{0}, y_{0} \in X$ such that

$$
x_{0} \sqsubseteq F\left(x_{0}, y_{0}\right) \text { and } F\left(y_{0}, x_{0}\right) \sqsubseteq y_{0} .
$$

If $y_{0} \sqsubseteq x_{0}$, then $F$ has a coupled fixed point.

Very recently, Sintunavarat et al. [40] have weakened the condition of the mixed monotone property in results of Cho et al. [39] by using the concept of an $F$-invariant set (see the notion of an $F$-invariant set in Section 2). 
Theorem 1.4 ([40]) Let $(X, d)$ be a complete cone metric space. Let $q$ be a c-distance on $X$, $M$ be a nonempty subset of $X^{4}$ and $F: X \times X \rightarrow X$ be a continuous function such that

$$
q\left(F(x, y), F\left(x^{*}, y^{*}\right)\right) \preceq \frac{k}{2}\left(q\left(x, x^{*}\right)+q\left(y, y^{*}\right)\right)
$$

for some $k \in[0,1)$ and all $x, y, x^{*}, y^{*} \in X$ with

$$
\left(x, y, x^{*}, y^{*}\right) \in M \quad \text { or } \quad\left(x^{*}, y^{*}, x, y\right) \in M \text {. }
$$

If $M$ is F-invariant and there exist $x_{0}, y_{0} \in X$ such that

$$
\left(F\left(x_{0}, y_{0}\right), F\left(y_{0}, x_{0}\right), x_{0}, y_{0}\right) \in M,
$$

then $F$ has a coupled fixed point $(u, v)$. Moreover, if $(u, v, u, v) \in M$, then $q(v, v)=\theta$ and $q(u, u)=\theta$.

Theorem 1.5 ([40]) In addition to the hypotheses of Theorem 1.4, suppose that for any two elements $x$ and $y$ in $X$, we have

$$
(y, x, x, y) \in M \quad \text { or } \quad(x, y, y, x) \in M .
$$

Then the coupled fixed point has the form $(u, u)$, where $u \in X$.

Theorem 1.6 ([40]) Let $(X, d)$ be a complete cone metric space. Let $q$ be a c-distance on $X, M$ be a subset of $X^{4}$ and $F: X \times X \rightarrow X$ be a function such that

$$
q\left(F(x, y), F\left(x^{*}, y^{*}\right)\right) \preceq \frac{k}{4}\left(q\left(x, x^{*}\right)+q\left(y, y^{*}\right)\right)
$$

for some $k \in[0,1)$ and all $x, y, x^{*}, y^{*} \in X$ with

$$
\left(x, y, x^{*}, y^{*}\right) \in M \quad \text { or } \quad\left(x^{*}, y^{*}, x, y\right) \in M \text {. }
$$

Also, suppose that

(i) there exist $x_{0}, y_{0} \in X$ such that $\left(F\left(x_{0}, y_{0}\right), F\left(y_{0}, x_{0}\right), x_{0}, y_{0}\right) \in M$,

(ii) two sequences $\left\{x_{n}\right\},\left\{y_{n}\right\}$ with $\left(x_{n+1}, y_{n+1}, x_{n}, y_{n}\right) \in M$ for all $n \in \mathbb{N}$ and $\left\{x_{n}\right\} \rightarrow x$, $\left\{y_{n}\right\} \rightarrow y$, then $\left(x, y, y_{n}, x_{n}\right) \in M$ and $\left(y_{n}, x_{n}, y, x\right) \in M$ for all $n \in \mathbb{N}$.

If $M$ is an F-invariant set, then $F$ has a coupled fixed point.

Inspired by the results of Sintunavarat et al. [40], we prove some coupled fixed point theorems in cone metric spaces by using the concept of an $F$-invariant set and give some example which is not applied to the existence of a coupled fixed point by the results of Sintunavarat et al. [40], but can be applied to our results. Moreover, we show that our results can be applied to the result in partially ordered cone metric spaces. We also consider an application to illustrate our result is useful (see Section 4). 


\section{Preliminaries}

Throughout this paper $(X, \sqsubseteq)$ denotes a partially ordered set. By $x \sqsubset y$, we mean $x \sqsubseteq y$ but $x \neq y$. A mapping $f: X \rightarrow X$ is said to be non-decreasing (non-increasing) if for all $x, y \in X$, $x \sqsubseteq y$ implies $f(x) \sqsubseteq f(y)(f(y) \sqsubseteq f(x)$ respectively).

Definition 2.1 ([20]) Let ( $X$, ㄷ) be a partially ordered set. A mapping $F: X \times X \rightarrow X$ is said to have the mixed monotone property if $F$ is monotone non-decreasing in its first argument and is monotone non-increasing in its second argument; that is, for any $x, y \in X$,

$$
x_{1}, x_{2} \in X, \quad x_{1} \sqsubseteq x_{2} \quad \Longrightarrow \quad F\left(x_{1}, y\right) \sqsubseteq F\left(x_{2}, y\right)
$$

and

$$
y_{1}, y_{2} \in X, \quad y_{1} \sqsubseteq y_{2} \quad \Longrightarrow \quad F\left(x, y_{1}\right) \sqsupseteq F\left(x, y_{2}\right) .
$$

Definition 2.2 ([20]) Let $X$ be a nonempty set. An element $(x, y) \in X \times X$ is called a coupled fixed point of mapping $F: X \times X \rightarrow X$ if

$$
x=F(x, y) \quad \text { and } \quad y=F(y, x) .
$$

Next, we give some terminology of cone metric spaces and the concept of a $c$-distance in cone metric spaces due to Cho et al. [35] which is a generalization of a $w$-distance of Kada et al. [36].

Let $\left(E,\|\cdot\|_{E}\right)$ be a real Banach space, $\theta$ be a zero element in $E$ and $P$ be a proper nonempty subset of $E$. Then $P$ is called a cone if the following conditions are satisfied:

(1) $P$ is closed and $P \neq\{\theta\}$;

(2) $a, b \in \mathbb{R}^{+}, x, y \in P$ implies $a x+b y \in P$;

(3) $x \in P \cap(-P)$ implies $x=\theta$.

We shall always assume that the cone $P$ has a nonempty interior (such cones are called solid). For the cone $P$, define the partial ordering $\preceq$ with respect to $P$ by $x \preceq y$ if and only if $y-x \in P$. We write $x \prec y$ to indicate that $x \preceq y$ but $x \neq y$, while $x \ll y$ stand for $y-x \in \operatorname{int}(P)$, where $\operatorname{int}(P)$ is an interior of $P$.

It can be easily shown that $\lambda \operatorname{int}(P) \subseteq \operatorname{int}(P)$ for all positive scalars $\lambda$.

The cone $P$ is called normal if there is a number $K>0$ such that for all $x, y \in E$,

$$
0 \leq x \leq y \quad \Longrightarrow \quad\|x\|_{E} \leq K\|y\|_{E}
$$

The least positive number satisfying the above is called the normal constant of $P$. It is clear that $K \geq 1$.

In what follows, we always suppose that $E$ is a real Banach space with the cone $P$.

Definition 2.3 ([34]) Let $X$ be a nonempty set. Suppose that the mapping $d: X \times X \rightarrow E$ satisfies the following conditions:

(1) $\theta \preceq d(x, y)$ for all $x, y \in X$ and $d(x, y)=\theta$ if and only if $x=y$;

(2) $d(x, y)=d(y, x)$ for all $x, y \in X$;

(3) $d(x, y) \preceq d(x, z)+d(z, y)$ for all $x, y, z \in X$.

Then $d$ is called a cone metric on $X$ and $(X, d)$ is called a cone metric space. 
Definition 2.4 ([34] $)$ Let $(X, d)$ be a cone metric space. Let $\left\{x_{n}\right\}$ be a sequence in $X$ and $x \in X$.

(1) If for any $c \in X$ with $\theta \ll c$, there exists $N \in \mathbb{N}$ such that $d\left(x_{n}, x\right) \ll c$ for all $n \geq N$, then $\left\{x_{n}\right\}$ is said to be convergent to a point $x \in X$ and $x$ is the limit of $\left\{x_{n}\right\}$. We denote this by $\lim _{n \rightarrow \infty} x_{n}=x$ or $x_{n} \rightarrow x$ as $n \rightarrow \infty$.

(2) If for any $c \in E$ with $\theta \ll c$, there exists $N \in \mathbb{N}$ such that $d\left(x_{n}, x_{m}\right) \ll c$ for all $n, m \geq N$, then $\left\{x_{n}\right\}$ is called a Cauchy sequence in $X$.

(3) The space $(X, d)$ is called a complete cone metric space if every Cauchy sequence is convergent.

Definition 2.5 ([35]) Let $(X, d)$ be a cone metric space. Then a function $q: X \times X \rightarrow E$ is called a $c$-distance on $X$ if the following are satisfied:

(q1) $\theta \preceq q(x, y)$ for all $x, y \in X$;

(q2) $q(x, y) \preceq q(x, z)+q(z, y)$ for all $x, y, z \in X$;

(q3) for any $x \in X$, if there exists $u=u_{x} \in P$ such that $q\left(x, y_{n}\right) \preceq u$ for each $n \in \mathbb{N}$, then $q(x, y) \preceq u$ whenever $\left\{y_{n}\right\}$ is a sequence in $X$ converging to a point $y \in X$;

(q4) for any $c \in E$ with $\theta \ll c$, there exists $e \in E$ with $\theta \ll e$ such that $q(z, x) \ll e$ and $q(z, y) \ll c$ imply $d(x, y) \ll c$.

Remark 2.6 The $c$-distance $q$ is a $w$-distance on $X$ if we take $(X, d)$ is a metric space, $E=\mathbb{R}^{+}, P=[0, \infty)$ and (q3) is replaced by the following condition:

For any $x \in X, q(x, \cdot): X \rightarrow \mathbb{R}^{+}$is lower semi-continuous.

Therefore, every $w$-distance is a $c$-distance. But the converse is not true in a general case. Therefore, the $c$-distance is a generalization of the $w$-distance.

Example 2.7 Let $(X, d)$ be a cone metric space and $P$ be a normal cone. Define a mapping $q: X \times X \rightarrow E$ by $q(x, y)=d(x, y)$ for all $x, y \in X$. Then $q$ is a $c$-distance.

Example 2.8 Let $E=C_{\mathbb{R}}^{1}[0,1]$ with $\|x\|_{E}=\|x\|_{\infty}+\left\|x^{\prime}\right\|_{\infty}$ and $P=\{x \in E: x(t) \geq 0$ on $[0,1]\}$ (this cone is not normal). Let $X=[0, \infty)$ and define a mapping $d: X \times X \rightarrow E$ by

$$
d(x, y)=|x-y| \varphi
$$

for all $x, y \in X$, where $\varphi:[0,1] \rightarrow \mathbb{R}$ such that $\varphi(t)=e^{t}$. Then $(X, d)$ is a cone metric space. Define a mapping $q: X \times X \rightarrow E$ by

$$
q(x, y)=(x+y) \varphi
$$

for all $x, y \in X$. Then $q$ is a $c$-distance.

Example 2.9 Let $(X, d)$ be a cone metric space and $P$ be a normal cone. Define a mapping $q: X \times X \rightarrow E$ by

$$
q(x, y)=d(u, y)
$$

for all $x, y \in X$, where $u$ is a fixed point in $X$. Then $q$ is a $c$-distance. 
Example 2.10 Let $E=\mathbb{R}$ and $P=\{x \in E: x \geq 0\}$. Let $X=[0, \infty)$ and define a mapping $d: X \times X \rightarrow E$ by

$$
d(x, y)=|x-y|
$$

for all $x, y \in X$. Then $(X, d)$ is a cone metric space. Define a mapping $q: X \times X \rightarrow E$ by

$$
q(x, y)=y
$$

for all $x, y \in X$. Then $q$ is a $c$-distance.

Remark 2.11 From Examples 2.9 and 2.10, we have the following important results for a $c$-distance $q$ :

- $q(x, y)=q(y, x)$ does not necessarily hold.

- $q(x, y)=\theta$ is not necessarily equivalent to $x=y$ for all $x, y \in X$.

The following lemma is crucial in proving main results.

Lemma $2.12([35])$ Let $(X, d)$ be a cone metric space and $q$ be a c-distance on $X$. Let $\left\{x_{n}\right\}$ and $\left\{y_{n}\right\}$ be sequences in $X$ and $x, y, z \in X$. Suppose that $\left\{u_{n}\right\}$ is a sequence in $P$ converging to $\theta$. Then the following hold:

(1) If $q\left(x_{n}, y\right) \preceq u_{n}$ and $q\left(x_{n}, z\right) \preceq u_{n}$, then $y=z$.

(2) If $q\left(x_{n}, y_{n}\right) \preceq u_{n}$ and $q\left(x_{n}, z\right) \preceq u_{n}$, then $\left\{y_{n}\right\}$ converges to a point $z \in X$.

(3) If $q\left(x_{n}, x_{m}\right) \preceq u_{n}$ for each $m>n$, then $\left\{x_{n}\right\}$ is a Cauchy sequence in $X$.

(4) If $q\left(y, x_{n}\right) \preceq u_{n}$, then $\left\{x_{n}\right\}$ is a Cauchy sequence in $X$.

Next, we give the concept of an $F$-invariant set in a cone version due to Sintunavarat et al. [40].

Definition 2.13 ([40]) Let $(X, d)$ be a cone metric space and $F: X \times X \rightarrow X$ be a given mapping. Let $M$ be a nonempty subset of $X^{4}$. We say that $M$ is an $F$-invariant subset of $X^{4}$ if and only if for all $x, y, z, w \in X$, we have

$\left(F_{1}\right) \quad(x, y, z, w) \in M \Longleftrightarrow(w, z, y, x) \in M$;

$\left(F_{2}\right)(x, y, z, w) \in M \Longrightarrow(F(x, y), F(y, x), F(z, w), F(w, z)) \in M$.

We obtain that the set $M=X^{4}$ is trivially $F$-invariant.

Next example plays a key role in the proof of our main results in a partially ordered set.

Example 2.14 ([40]) Let $(X, d)$ be a cone metric space endowed with a partial order $\sqsubseteq$. Let $F: X \times X \rightarrow X$ be a mapping satisfying the mixed monotone property; that is, for all $x, y \in X$, we have

$$
x_{1}, x_{2} \in X, \quad x_{1} \sqsubseteq x_{2} \quad \Longrightarrow \quad F\left(x_{1}, y\right) \sqsubseteq F\left(x_{2}, y\right)
$$

and

$$
y_{1}, y_{2} \in X, \quad y_{1} \sqsubseteq y_{2} \quad \Longrightarrow \quad F\left(x, y_{1}\right) \sqsupseteq F\left(x, y_{2}\right) .
$$


Define the subset $M \subseteq X^{4}$ by

$$
M=\{(a, b, c, d): c \sqsubseteq a, b \sqsubseteq d\}
$$

Then, $M$ is $F$-invariant of $X^{4}$.

\section{Main results}

First, we show the weakness of Theorem 1.4 with the following example.

Example 3.1 Let $E=C_{\mathbb{R}}^{1}[0,1]$ with $\|x\|_{E}=\|x\|_{\infty}+\left\|x^{\prime}\right\|_{\infty}$ and $P=\{x \in E, x(t) \geq 0, t \in[0,1]\}$. Let $X=[0, \infty)$ (with usual order $\sqsubseteq$ ), and let $d: X \times X \rightarrow E$ be defined by $d(x, y)(t)=\mid x-$ $y \mid 2^{t}$. Then $(X, d)$ is a complete cone metric space. Let, further, $q: X \times X \rightarrow E$ be defined by $q(x, y)(t)=y 2^{t}$. It is easy to check that $q$ is a $c$-distance. Consider the mapping $F: X \times X \rightarrow$ $X$ by

$$
F(x, y)= \begin{cases}\frac{3}{5}(x+y) & \text { if } x \geq y \\ 0 & \text { if } x<y\end{cases}
$$

Let $M=X^{4}$ and so $M$ is an $F$-invariant subset of $X$. Now, we show that there is no $k \in[0,1)$ for which (1.4) holds. To prove this, suppose the contrary; that is, there is $k \in[0,1)$ such that

$$
q\left(F(x, y), F\left(x^{*}, y^{*}\right)\right) \preceq \frac{k}{2}\left(q\left(x, x^{*}\right)+q\left(y, y^{*}\right)\right)
$$

for all $x, y, x^{*}, y^{*} \in X$ with

$$
\left(x, y, x^{*}, y^{*}\right) \in M \quad \text { or } \quad\left(x^{*}, y^{*}, x, y\right) \in M \text {. }
$$

Take $x=0, y=1, x^{*}=1$ and $y^{*}=0$. Then

$$
q(F(0,1), F(1,0))(t) \preceq \frac{k}{2}(q(0,1)+q(1,0))(t) .
$$

This implies

$$
F(1,0) 2^{t}=\frac{3}{5} 2^{t} \preceq \frac{k}{2} 2^{t} .
$$

Hence, $k \geq \frac{6}{5}$ is a contradiction. Therefore, there is no $k$ for which (1.4) holds.

Moreover, for $y_{1}=\frac{1}{3}$ and $y_{2}=\frac{1}{2}$, we have for $x=1$, we get $y_{1}=\frac{1}{3} \sqsubseteq \frac{1}{2}=y_{2}$ but

$$
F\left(x, y_{1}\right)=\frac{4}{5} \sqsubseteq \frac{9}{10}=F\left(x, y_{2}\right) \text {. }
$$

So, the mapping $F$ does not satisfy the mixed monotone property. Therefore, main theorems of Cho et al. [39] cannot be used to reach this conclusion.

The following theorem is the extension of Theorem 1.4 
Theorem 3.2 Let $(X, d)$ be a complete cone metric space. Let $q$ be a c-distance on $X, M$ be a nonempty subset of $X^{4}$ and $F: X \times X \rightarrow X$ be a continuous function such that

$$
q\left(F(x, y), F\left(x^{*}, y^{*}\right)\right)+q\left(F(y, x), F\left(y^{*}, x^{*}\right)\right) \preceq k\left(q\left(x, x^{*}\right)+q\left(y, y^{*}\right)\right)
$$

for some $k \in[0,1)$ and all $x, y, x^{*}, y^{*} \in X$ with

$$
\left(x, y, x^{*}, y^{*}\right) \in M \quad \text { or } \quad\left(x^{*}, y^{*}, x, y\right) \in M \text {. }
$$

If $M$ is $F$-invariant and there exist $x_{0}, y_{0} \in X$ such that

$$
\left(F\left(x_{0}, y_{0}\right), F\left(y_{0}, x_{0}\right), x_{0}, y_{0}\right) \in M,
$$

then $F$ has a coupled fixed point $(u, v)$. Moreover, if $(u, v, u, v) \in M$, then $q(u, u)=\theta$ and $q(v, v)=\theta$.

Proof Since $F(X \times X) \subseteq X$, we can construct two sequences $\left\{x_{n}\right\}$ and $\left\{y_{n}\right\}$ in $X$ such that

$$
x_{n}=F\left(x_{n-1}, y_{n-1}\right) \quad \text { and } \quad y_{n}=F\left(y_{n-1}, x_{n-1}\right) \quad \text { for all } n \in \mathbb{N} \text {. }
$$

Since $\left(F\left(x_{0}, y_{0}\right), F\left(y_{0}, x_{0}\right), x_{0}, y_{0}\right)=\left(x_{1}, y_{1}, x_{0}, y_{0}\right) \in M$ and $M$ is an $F$-invariant set, we get

$$
\left(F\left(x_{1}, y_{1}\right), F\left(y_{1}, x_{1}\right), F\left(x_{0}, y_{0}\right), F\left(y_{0}, x_{0}\right)\right)=\left(x_{2}, y_{2}, x_{1}, y_{1}\right) \in M \text {. }
$$

Again, using the fact that $M$ is an $F$-invariant set, we have

$$
\left(F\left(x_{2}, y_{2}\right), F\left(y_{2}, x_{2}\right), F\left(x_{1}, y_{1}\right), F\left(y_{1}, x_{1}\right)\right)=\left(x_{3}, y_{3}, x_{2}, y_{2}\right) \in M \text {. }
$$

By repeating the argument similar to the above, we get

$$
\left(F\left(x_{n-1}, y_{n-1}\right), F\left(y_{n-1}, x_{n-1}\right), x_{n-1}, y_{n-1}\right)=\left(x_{n}, y_{n}, x_{n-1}, y_{n-1}\right) \in M
$$

for all $n \in \mathbb{N}$. From (3.1), we have

$$
\begin{aligned}
q\left(x_{n}, x_{n+1}\right)+q\left(y_{n}, y_{n+1}\right) & \preceq q\left(F\left(x_{n-1}, y_{n-1}\right), F\left(x_{n}, y_{n}\right)\right)+q\left(F\left(y_{n-1}, x_{n-1}\right), F\left(y_{n}, x_{n}\right)\right) \\
& \preceq k\left(q\left(x_{n-1}, x_{n}\right)+q\left(y_{n-1}, y_{n}\right)\right) .
\end{aligned}
$$

We repeat the above process for $n$-times, we get

$$
q\left(x_{n}, x_{n+1}\right)+q\left(y_{n}, y_{n+1}\right) \preceq k^{n}\left(q\left(x_{0}, x_{1}\right)+q\left(y_{0}, y_{1}\right)\right) .
$$

From (3.4), we can conclude that

$$
q\left(x_{n}, x_{n+1}\right) \preceq k^{n}\left(q\left(x_{0}, x_{1}\right)+q\left(y_{0}, y_{1}\right)\right)
$$


and

$$
q\left(y_{n}, y_{n+1}\right) \preceq k^{n}\left(q\left(x_{0}, x_{1}\right)+q\left(y_{0}, y_{1}\right)\right) .
$$

Let $m, n \in \mathbb{N}$ with $m>n$. Since

$$
\begin{aligned}
& q\left(x_{n}, x_{m}\right) \preceq \sum_{i=n}^{m-1} q\left(x_{i}, x_{i+1}\right), \\
& q\left(y_{n}, y_{m}\right) \preceq \sum_{i=n}^{m-1} q\left(y_{i}, y_{i+1}\right)
\end{aligned}
$$

and $0 \leq k<1$, we have

$$
q\left(x_{n}, x_{m}\right) \preceq \frac{k^{n}}{1-k}\left(q\left(x_{0}, x_{1}\right)+q\left(y_{0}, y_{1}\right)\right)
$$

and

$$
q\left(y_{n}, y_{m}\right) \preceq \frac{k^{n}}{1-k}\left(q\left(x_{0}, x_{1}\right)+q\left(y_{0}, y_{1}\right)\right) .
$$

Using Lemma 2.12(3), we have $\left\{x_{n}\right\}$ and $\left\{y_{n}\right\}$ are Cauchy sequences in $(X, d)$. By completeness of $X$, we get $x_{n} \rightarrow u$ and $y_{n} \rightarrow v$ as $n \rightarrow \infty$ for some $u, v \in X$.

Since $F$ is continuous, taking $n \rightarrow \infty$ in (3.2), we get

$$
\lim _{n \rightarrow \infty} x_{n+1}=\lim _{n \rightarrow \infty} F\left(x_{n}, y_{n}\right)=F\left(\lim _{n \rightarrow \infty} x_{n}, \lim _{n \rightarrow \infty} y_{n}\right)=F(u, v)
$$

and

$$
\lim _{n \rightarrow \infty} y_{n+1}=\lim _{n \rightarrow \infty} F\left(y_{n}, x_{n}\right)=F\left(\lim _{n \rightarrow \infty} y_{n}, \lim _{n \rightarrow \infty} x_{n}\right)=F(v, u)
$$

By the uniqueness of the limits, we get $u=F(u, v)$ and $v=F(v, u)$. Therefore, $(u, v)$ is a coupled fixed point of $F$.

Finally, we assume that $(u, v, u, v) \in M$. By (3.1), we have

$$
q(u, u)+q(v, v)=q(F(u, v), F(u, v))+q(F(v, u), F(v, u)) \preceq k(q(u, u)+q(v, v)) .
$$

Since $0 \leq k<1$, we conclude that $q(u, u)+q(v, v)=\theta$ and hence $q(u, u)=\theta$ and $q(v, v)=\theta$. This completes the proof.

Remark 3.3 We obtain that the mapping $F$ in Example 3.1 has a coupled fixed point. Indeed, for all $x, y, x^{*}, y^{*} \in X$ with

$$
\left(x, y, x^{*}, y^{*}\right) \in M \quad \text { or } \quad\left(x^{*}, y^{*}, x, y\right) \in M
$$

we have

$$
q\left(F(x, y), F\left(x^{*}, y^{*}\right)\right)+q\left(F(y, x), F\left(y^{*}, x^{*}\right)\right) \preceq \frac{3}{5}\left(q\left(x, x^{*}\right)+q\left(y, y^{*}\right)\right) .
$$


Also, we note that there exists points $0,1 \in X$ such that $(F(0,1), F(1,0), 0,1) \in M$. Thus, by Theorem 3.2, we have $F$ has a coupled fixed point that is a point $(0,0)$.

Theorem 3.4 In addition to the hypotheses of Theorem 3.2, suppose that for any two elements $x$ and $y$ in $X$, we have

$$
(y, x, x, y) \in M \quad \text { or } \quad(x, y, y, x) \in M
$$

Then the coupled fixed point has the form $(u, u)$, where $u \in X$.

Proof As in the proof of Theorem 3.2, there exists a coupled fixed point $(u, v) \in X \times X$. Hence,

$$
u=F(u, v) \text { and } \quad v=F(v, u) \text {. }
$$

Moreover, $q(u, u)=\theta$ and $q(v, v)=\theta$ if $(u, v, u, v) \in M$.

From the additional hypothesis, we have $(u, v, v, u) \in M$ or $(v, u, u, v) \in M$. By (3.1), we get

$$
q(u, v)+q(v, u)=q(F(u, v), F(v, u))+q(F(v, u), F(u, v)) \preceq k(q(u, v)+q(v, u)) .
$$

Since $0 \leq k<1$, we get $q(u, v)+q(v, u)=\theta$. Therefore, $q(u, v)=\theta$ and $q(v, u)=\theta$.

Let $u_{n}=\theta$ and $x_{n}=u$. Then

$$
q\left(x_{n}, u\right) \preceq u_{n}
$$

and

$$
q\left(x_{n}, v\right) \preceq u_{n}
$$

From Lemma 2.12(1), we have $u=v$. Therefore, the coupled fixed point of $F$ has the form $(u, u)$. This completes the proof.

Theorem 3.5 Let $(X, d)$ be a complete cone metric space. Let $q$ be a c-distance on $X, M$ be a subset of $X^{4}$ and $F: X \times X \rightarrow X$ be a function such that

$$
q\left(F(x, y), F\left(x^{*}, y^{*}\right)\right)+q\left(F(y, x), F\left(y^{*}, x^{*}\right)\right) \preceq k\left(q\left(x, x^{*}\right)+q\left(y, y^{*}\right)\right)
$$

for some $k \in[0,1)$ and all $x, y, x^{*}, y^{*} \in X$ with

$$
\left(x, y, x^{*}, y^{*}\right) \in M \quad \text { or } \quad\left(x^{*}, y^{*}, x, y\right) \in M \text {. }
$$

Also, suppose that

(i) there exist $x_{0}, y_{0} \in X$ such that $\left(F\left(x_{0}, y_{0}\right), F\left(y_{0}, x_{0}\right), x_{0}, y_{0}\right) \in M$,

(ii) two sequences $\left\{x_{n}\right\},\left\{y_{n}\right\}$ with $\left(x_{n+1}, y_{n+1}, x_{n}, y_{n}\right) \in M$ for all $n \in \mathbb{N}$ and $\left\{x_{n}\right\} \rightarrow x$, $\left\{y_{n}\right\} \rightarrow y$, then $\left(x, y, x_{n}, y_{n}\right) \in M$ for all $n \in \mathbb{N}$. 
If $M$ is an F-invariant set, then $F$ has a coupled fixed point. Moreover, if $(u, v, u, v) \in M$, then $q(u, u)=\theta$ and $q(v, v)=\theta$.

Proof As in the proof of Theorem 3.2, we can construct two Cauchy sequences $\left\{x_{n}\right\}$ and $\left\{y_{n}\right\}$ in $X$ such that

$$
\left(x_{n}, y_{n}, x_{n-1}, y_{n-1}\right) \in M
$$

for all $n \in \mathbb{N}$. Moreover, we have that $\left\{x_{n}\right\}$ converges to a point $u \in X$ and $\left\{y_{n}\right\}$ converges to $v \in X$,

$$
q\left(x_{n}, x_{m}\right) \preceq \frac{k^{n}}{1-k}\left(q\left(x_{0}, x_{1}\right)+q\left(y_{0}, y_{1}\right)\right)
$$

and

$$
q\left(y_{n}, y_{m}\right) \preceq \frac{k^{n}}{1-k}\left(q\left(x_{0}, x_{1}\right)+q\left(y_{0}, y_{1}\right)\right)
$$

for each $m>n \geq 1$. By (q3), we have

$$
q\left(x_{n}, u\right) \preceq \frac{k^{n}}{1-k}\left(q\left(x_{0}, x_{1}\right)+q\left(y_{0}, y_{1}\right)\right)
$$

and

$$
q\left(y_{n}, v\right) \preceq \frac{k^{n}}{1-k}\left(q\left(x_{0}, x_{1}\right)+q\left(y_{0}, y_{1}\right)\right)
$$

and so

$$
q\left(x_{n}, u\right)+q\left(y_{n}, v\right) \preceq \frac{2 k^{n}}{1-k}\left(q\left(x_{0}, x_{1}\right)+q\left(y_{0}, y_{1}\right)\right) .
$$

By the assumption (ii), we have $\left(u, v, x_{n}, y_{n}\right) \in M$. From (3.7) and (3.10), we have

$$
\begin{aligned}
q\left(x_{n}, F(u, v)\right)+q\left(y_{n}, F(v, u)\right) & =q\left(F\left(x_{n-1}, y_{n-1}\right), F(u, v)\right)+q\left(F\left(y_{n-1}, x_{n-1}\right), F(v, u)\right) \\
& \preceq k\left(q\left(x_{n-1}, u\right)+q\left(y_{n-1}, v\right)\right) \\
& \preceq k \cdot \frac{2 k^{n-1}}{1-k}\left(q\left(x_{0}, x_{1}\right)+q\left(y_{0}, y_{1}\right)\right) \\
& =\frac{2 k^{n}}{1-k}\left(q\left(x_{0}, x_{1}\right)+q\left(y_{0}, y_{1}\right)\right) .
\end{aligned}
$$

Therefore, we have

$$
q\left(x_{n}, F(u, v)\right) \preceq \frac{2 k^{n}}{1-k}\left(q\left(x_{0}, x_{1}\right)+q\left(y_{0}, y_{1}\right)\right)
$$

and

$$
q\left(y_{n}, F(v, u)\right) \preceq \frac{2 k^{n}}{1-k}\left(q\left(x_{0}, x_{1}\right)+q\left(y_{0}, y_{1}\right)\right) .
$$


From (3.10), we get

$$
q\left(x_{n}, u\right) \preceq \frac{2 k^{n}}{1-k}\left(q\left(x_{0}, x_{1}\right)+q\left(y_{0}, y_{1}\right)\right)
$$

and

$$
q\left(y_{n}, v\right) \preceq \frac{2 k^{n}}{1-k}\left(q\left(x_{0}, x_{1}\right)+q\left(y_{0}, y_{1}\right)\right) .
$$

Since (3.11), (3.12), (3.13) and (3.14) hold, by using Lemma 2.12(1), we get $u=F(u, v)$ and $v=F(v, u)$. Therefore, $(u, v)$ is a coupled fixed point of $F$. The proof of $q(u, u)=\theta$ and $q(v, v)=\theta$ is the same as the proof in Theorem 3.2. This completes the proof.

The following theorem can be proved in the same way as Theorem 3.4 .

Theorem 3.6 In addition to the hypotheses of Theorem 3.5, suppose that for any two elements $x$ and $y$ in $X$, we have

$$
(y, x, x, y) \in M \quad \text { or } \quad(x, y, y, x) \in M
$$

Then the coupled fixed point has the form $(u, u)$, where $u \in X$.

Remark 3.7 Since the relations (1.4) and (1.5) imply (3.1), we can apply Theorems 3.2, 3.4 and 3.5 to the main result of Sintunavarat et al. [40].

Next, we apply Theorems 3.2, 3.4, 3.5 and 3.6 to the results in a partially ordered cone metric spaces.

Corollary 3.8 Let $(X, \sqsubseteq)$ be a partially ordered set and suppose that $(X, d)$ is a complete cone metric space. Let $q$ be a c-distance on $X$ and $F: X \times X \rightarrow X$ be a continuous function having the mixed monotone property such that

$$
q\left(F(x, y), F\left(x^{*}, y^{*}\right)\right)+q\left(F(y, x), F\left(y^{*}, x^{*}\right)\right) \preceq k\left(q\left(x, x^{*}\right)+q\left(y, y^{*}\right)\right)
$$

for some $k \in[0,1)$ and all $x, y, x^{*}, y^{*} \in X$ with

$$
\left(x \sqsubseteq x^{*}\right) \wedge\left(y \sqsupseteq y^{*}\right) \quad \text { or } \quad\left(x \sqsupseteq x^{*}\right) \wedge\left(y \sqsubseteq y^{*}\right) .
$$

If there exist $x_{0}, y_{0} \in X$ such that

$$
x_{0} \sqsubseteq F\left(x_{0}, y_{0}\right) \text { and } F\left(y_{0}, x_{0}\right) \sqsubseteq y_{0} \text {, }
$$

then $F$ has a coupled fixed point $(u, v)$. Moreover, we have $q(v, v)=\theta$ and $q(u, u)=\theta$.

Proof Let $M=\{(a, b, c, d): c \sqsubseteq a, b \sqsubseteq d\} \subseteq X^{4}$. We obtain that $M$ is an $F$-invariant set. By (3.15), we have

$$
q\left(F(x, y), F\left(x^{*}, y^{*}\right)\right)+q\left(F(y, x), F\left(y^{*}, x^{*}\right)\right) \preceq k\left(q\left(x, x^{*}\right)+q\left(y, y^{*}\right)\right)
$$


for some $k \in[0,1)$ and all $x, y, x^{*}, y^{*} \in X$ with $\left(x, y, x^{*}, y^{*}\right) \in M$ or $\left(x^{*}, y^{*}, x, y\right) \in M$. Now, all the hypotheses of Theorem 3.2 hold. Thus, $F$ has a coupled fixed point.

Corollary 3.9 In addition to the hypotheses of Corollary 3.8, suppose that for any two elements $x$ and $y$ in $X$, we have $x$ and $y$ are comparable. Then the coupled fixed point has the form $(u, u)$, where $u \in X$.

Proof This result is obtained by Theorem 3.4.

Corollary 3.10 Let $(X, \sqsubseteq)$ be a partially ordered set and suppose that $(X, d)$ is a complete cone metric space. Let $q$ be a c-distance on $X$ and $F: X \times X \rightarrow X$ be a function having the mixed monotone property such that

$$
q\left(F(x, y), F\left(x^{*}, y^{*}\right)\right)+q\left(F(y, x), F\left(y^{*}, x^{*}\right)\right) \preceq k\left(q\left(x, x^{*}\right)+q\left(y, y^{*}\right)\right)
$$

for some $k \in[0,1)$ and all $x, y, x^{*}, y^{*} \in X$ with

$$
\left(x \sqsubseteq x^{*}\right) \wedge\left(y \sqsupseteq y^{*}\right) \quad \text { or } \quad\left(x \sqsupseteq x^{*}\right) \wedge\left(y \sqsubseteq y^{*}\right) \text {. }
$$

Also, suppose that $X$ has the following properties:

(a) if $\left\{x_{n}\right\}$ is a non-decreasing sequence in $X$ with $x_{n} \rightarrow x$, then $x_{n} \sqsubseteq x$ for all $n \in \mathbb{N}$;

(b) if $\left\{y_{n}\right\}$ is a non-increasing sequence in $X$ with $y_{n} \rightarrow y$, then $y \sqsubseteq y_{n}$ for all $n \in \mathbb{N}$.

If there exist $x_{0}, y_{0} \in X$ such that

$$
x_{0} \sqsubseteq F\left(x_{0}, y_{0}\right) \text { and } F\left(y_{0}, x_{0}\right) \sqsubseteq y_{0} \text {, }
$$

then $F$ has a coupled fixed point $(u, v)$. Moreover, we have $q(v, v)=\theta$ and $q(u, u)=\theta$.

Proof Let $M=\{(a, b, c, d): c \sqsubseteq a, b \sqsubseteq d\} \subseteq X^{4}$. We obtain that $M$ is an $F$-invariant set. By (3.16), we have

$$
q\left(F(x, y), F\left(x^{*}, y^{*}\right)\right)+q\left(F(y, x), F\left(y^{*}, x^{*}\right)\right) \preceq k\left(q\left(x, x^{*}\right)+q\left(y, y^{*}\right)\right)
$$

for some $k \in[0,1)$ and all $x, y, x^{*}, y^{*} \in X$ with $\left(x, y, x^{*}, y^{*}\right) \in M$ or $\left(x^{*}, y^{*}, x, y\right) \in M$. From assumptions (a) and (b), we get two sequences $\left\{x_{n}\right\},\left\{y_{n}\right\}$, with $\left\{x_{n}\right\}$ being a non-decreasing sequence in $X$ with $x_{n} \rightarrow x$ and $\left\{y_{n}\right\}$ being a non-increasing sequence in $X$ with $y_{n} \rightarrow y$,

$$
x_{0} \sqsubseteq x_{1} \sqsubseteq \cdots \sqsubseteq x_{n} \sqsubseteq \cdots \sqsubseteq x
$$

and

$$
y_{0} \sqsupseteq y_{1} \sqsupseteq \cdots \sqsupseteq y_{n} \sqsupseteq \cdots \sqsupseteq y
$$

for all $n \in \mathbb{N}$. Therefore, we get the condition (ii) in Theorem 3.5 holds. Now, all the hypotheses of Theorem 3.5 hold. Thus, $F$ has a coupled fixed point.

Corollary 3.11 In addition to the hypotheses of Corollary 3.10, suppose that for any two elements $x$ and $y$ in $X$, we have $x$ and $y$ are comparable. Then the coupled fixed point has the form $(u, u)$, where $u \in X$. 


\section{Applications}

In this section, we apply our theorem to the existence theorem for a solution of the following integral equations:

$$
\begin{aligned}
& x(t)=\int_{0}^{T} f(t, x(s), y(s)) d s, \quad t \in[0, T] ; \\
& y(t)=\int_{0}^{T} f(t, y(s), x(s)) d s, \quad t \in[0, T],
\end{aligned}
$$

where $T>0$ and $f:[0, T] \times \mathbb{R} \times \mathbb{R} \rightarrow \mathbb{R}$.

In what follows, we always let $C([0, T], \mathbb{R})$ denote the class of $\mathbb{R}$-valued continuous functions on the interval $[0, T]$, where $T$ is a real number such that $T>0$.

Definition 4.1 An element $\alpha, \beta \in C([0, T], \mathbb{R}) \times C([0, T], \mathbb{R})$ is called a coupled lower and upper solution of the integral equation (4.1) if $\alpha(t) \leq \beta(t)$ and

$$
\alpha(t) \leq \int_{0}^{T} f(t, \alpha(s), \beta(s)) d s
$$

and

$$
\beta(t) \geq \int_{0}^{T} f(t, \beta(s), \alpha(s)) d s
$$

for all $t \in[0, T]$.

Now, we consider the following assumptions:

(a) $f:[0, T] \times \mathbb{R} \times \mathbb{R} \rightarrow \mathbb{R}$ is continuous;

(b) for all $t \in[0, T]$ and for all $x, y, x^{*}, y^{*} \in \mathbb{R}$ for which $x^{*} \leq x$ and $y \leq y^{*}$, we have

$$
0 \leq f(t, x, y)-f\left(t, x^{*}, y^{*}\right) \leq \frac{1}{T} \varphi\left(\frac{x-x^{*}+y^{*}-y}{2}\right)
$$

where $\varphi:[0, \infty) \rightarrow[0, \infty)$ is continuous non-decreasing and satisfies: there exists $0 \leq k<1$ such that

$$
\varphi(r) \leq k r \quad \forall r \geq 0
$$

Next, we give the existence theorem for a solution of the integral equations (4.1).

Theorem 4.2 Suppose that assumptions (a) and (b) hold. Then the existence of a coupled lower and upper solution for (4.1) provides the existence of a solution $(u, v) \in C([0, T], \mathbb{R}) \times$ $C([0, T], \mathbb{R})$ for the integral equations (4.1).

Proof Let $E=\mathbb{R}^{2}$ and $P \subseteq E$ be the cone defined by

$$
P=\left\{(x, y) \in \mathbb{R}^{2} \mid x \geq 0, y \geq 0\right\} .
$$


We endow $X$ with the cone metric $d: X \times X \rightarrow E$ defined by

$$
d(x, y)=\left(\sup _{t \in[0, T]}|x(t)-y(t)|, \sup _{t \in[0, T]}|x(t)-y(t)|\right), \quad \forall u, v \in X .
$$

It is clear that $(X, d)$ is a complete cone metric space. Let $q(x, y)=d(x, y)$ for all $x, y \in X$. Then, $q$ is a $c$-distance.

Define the self-mapping $F: C([0, T], \mathbb{R}) \times C([0, T], \mathbb{R}) \rightarrow C([0, T], \mathbb{R})$ by

$$
F(x, y)(t)=\int_{0}^{T} f(t, x(s), y(s)) d s, \quad x, y \in C([0, T], \mathbb{R}), t \in[0, T] .
$$

Let $M=\left\{\left(x, y, x^{*}, y^{*}\right) \in X^{4}: x^{*}(t) \leq x(t)\right.$ and $y(t) \leq y^{*}(t)$ for all $\left.t \in[0, T]\right\}$.

Next, we prove that $M$ is an $F$-invariant subset of $X^{4}$. It obvious that $M$ satisfies $\left(F_{1}\right)$. Now, we show that $\left(F_{2}\right)$ holds. Let $\left(x, y, x^{*}, y^{*}\right) \in M$ and then $x^{*}(t) \leq x(t)$ and $y(t) \leq y^{*}(t)$ for all $t \in[0, T]$. By (b), for all $t \in[0, T]$, we have

$$
0 \leq f(t, x(t), y(t))-f\left(t, x^{*}(t), y^{*}(t)\right)
$$

and

$$
0 \leq f\left(t, y^{\prime \prime}(t), x^{*}(t)\right)-f(t, y(t), x(t))
$$

From (4.2), we get

$$
f\left(t, x^{*}(t), y^{\prime \prime}(t)\right) \leq f(t, x(t), y(t))
$$

and so

$$
\int_{0}^{T} f\left(t, x^{\prime \prime}(s), y^{\prime \prime}(s)\right) d s \leq \int_{0}^{T} f(t, x(s), y(s)) d s .
$$

This implies that

$$
F\left(x^{*}, y^{*}\right)(t) \leq F(x, y)(t)
$$

Similarly, from (4.3), we get

$$
F(y, x)(t) \leq F\left(y^{*}, x^{*}\right)(t)
$$

From (4.4) and (4.5), we get $\left(F(x, y), F(y, x), F\left(x^{*}, y^{*}\right), F\left(y^{*}, x^{*}\right)\right) \in M$, and thus $M$ satisfies $\left(F_{2}\right)$. Therefore, $M$ is an $F$-invariant subset of $X^{4}$.

Now, let $\left(x, y, x^{*}, y^{*}\right) \in M$ and so $x^{*}(t) \leq x(t)$ and $y(t) \leq y^{*}(t)$ for all $t \in[0, T]$. Using (b), for all $t \in[0, T]$, we have

$$
\begin{aligned}
& \left|F(x, y)(t)-F\left(x^{*}, y^{*}\right)(t)\right| \\
& \quad=\int_{0}^{T}\left[f(t, x(s), y(s))-f\left(t, x^{*}(s), y^{* \prime}(s)\right)\right] d s
\end{aligned}
$$




$$
\begin{aligned}
& \leq \frac{1}{T} \int_{0}^{T} \varphi\left(\frac{x(s)-x^{*}(s)+y^{*}(s)-y(s)}{2}\right) d s \\
& \leq \frac{1}{T} \int_{0}^{T} \varphi\left(\frac{\sup _{z \in[0, T]}\left|x(z)-x^{* \prime}(z)\right|+\sup _{z \in[0, T]}\left|y(z)-y^{* \prime}(z)\right|}{2}\right) d s \\
& =\varphi\left(\frac{\sup _{z \in[0, T]}\left|x(z)-x^{*}(z)\right|+\sup _{z \in[0, T]}\left|y(z)-y^{\prime \prime}(z)\right|}{2}\right) \\
& \leq k\left[\frac{\sup _{z \in[0, T]}\left|x(z)-x^{*}(z)\right|+\sup _{z \in[0, T]}\left|y(z)-y^{*}(z)\right|}{2}\right],
\end{aligned}
$$

which implies that

$$
\begin{aligned}
& \sup _{t \in[0, T]}\left|F(x, y)(t)-F\left(x^{*}, y^{*}\right)(t)\right| \\
& \quad \leq k\left[\frac{\sup _{z \in[0, T]}\left|x(z)-x^{*}(z)\right|+\sup _{z \in[0, T]}\left|y(z)-y^{*}(z)\right|}{2}\right] .
\end{aligned}
$$

Similarly, we can get

$$
\begin{aligned}
& \sup _{t \in[0, T]}\left|F(y, x)(t)-F\left(y^{\prime \prime}, x^{*}\right)(t)\right| \\
& \quad \leq k\left[\frac{\sup _{z \in[0, T]}\left|x(z)-x^{\prime \prime}(z)\right|+\sup _{z \in[0, T]}\left|y(z)-y^{\prime \prime}(z)\right|}{2}\right] .
\end{aligned}
$$

Adding up (4.6) and (4.7), we get

$$
\begin{aligned}
& \sup _{t \in[0, T]}\left|F(x, y)(t)-F\left(x^{*}, y^{*}\right)(t)\right|+\sup _{t \in[0, T]}\left|F(y, x)(t)-F\left(y^{*}, x^{*}\right)(t)\right| \\
& \quad \leq k\left[\sup _{z \in[0, T]}\left|x(z)-x^{*}(z)\right|+\sup _{z \in[0, T]}\left|y(z)-y^{*}(z)\right|\right] .
\end{aligned}
$$

Thus,

$$
q\left(F(x, y), F\left(x^{*}, y^{*}\right)\right)+q\left(F(y, x), F\left(y^{*}, x^{*}\right)\right) \preceq k\left[q\left(x, x^{*}\right)+q\left(y, y^{*}\right)\right]
$$

for all $\left(x, y, x^{*}, y^{*}\right) \in M$. This implies that the condition (3.7) of Theorem 3.5 is satisfied.

Now, let $(\alpha, \beta)$ be a coupled lower and upper solution of the integral equations (4.1), then we have $\alpha(t) \leq F(\alpha, \beta)(t)$ and $\beta(t) \leq F(\beta, \alpha)(t)$ for all $t \in[0, T]$, that is, $\alpha \leq F(\alpha, \beta)$ and $\beta \geq$ $F(\beta, \alpha)$. Therefore, $(F(\alpha, \beta), F(\beta, \alpha), \alpha, \beta) \in M$, and then the condition (i) in Theorem 3.5 is satisfied. Moreover, it is easy to see that the condition (ii) in Theorem 3.5 is also satisfied.

Finally, applying our Theorem 3.5, we get the desired result.

\section{Competing interests}

The authors declare that they have no competing interests.

\section{Authors' contributions}

All authors contributed equally and significantly in writing this paper. All authors read and approved the final manuscript.

\section{Author details}

'Department of Mathematics, Atilim University, Incek, Ankara 06836, Turkey. ${ }^{2}$ Department of Mathematics, Faculty of Science, King Mongkut's University of Technology Thonburi (KMUTT), Bangkok, 10140, Thailand. 


\section{Acknowledgements}

This work was supported by the Higher Education Research Promotion and National Research University Project of Thailand, Office of the Higher Education Commission. The third author would like to thank the Research Professional Development Project under the Science Achievement Scholarship of Thailand (SAST).

\section{Received: 19 July 2012 Accepted: 15 October 2012 Published: 29 October 2012}

\section{References}

1. Guo, Y: A generalization of Banach's contraction principle for some non-obviously contractive operators in a cone metric space. Turkish J. Math. 36, 297-304 (2012)

2. Yantir, A, Topal, SG: Positive solutions of nonlinear m-point BVP on time scales. Int. J. Difference Equ. 3(1), 179-194 (2008)

3. Border, KC: Fixed Point Theorems with Applications to Economics and Game Theory. Cambridge University Press, New York (1985)

4. Cataldo, A, Lee, EA, Liu, X, Matsikoudis, ED, Zheng, H: A constructive fixed point theorem and the feedback semantics of timed systems. Tech. Report UCB/EECS-2006-4, EECS Dept., University of California, Berkeley (2006)

5. Hyvärinen, A: Fast and robust fixed-point algorithms for independent component analysis. IEEE Trans. Neural Netw. 10(3), 626-634 (1999)

6. Noumsi, A, Derrien, S, Quinton, P: Acceleration of a content based image retrieval application on the RDISK cluster. In: IEEE International Parallel and Distributed Processing Symposium. April (2006)

7. Abbas, M, Khan, SH, Nazir, T: Common fixed points of R-weakly commuting maps in generalized metric spaces. Fixed Point Theory Appl. 2011, 41 (2011)

8. Boyd, DW, Wong, JSW: On nonlinear contractions. Proc. Am. Math. Soc. 20, 458-464 (1969)

9. Mongkolkeha, C, Kumam, P: Fixed point and common fixed point theorems for generalized weak contraction mappings of integral type in modular spaces. Int. J. Math. Math. Sci. 2011, 705943 (2011)

10. Mongkolkeha, C, Kumam, P: Fixed point theorems for generalized asymptotic pointwise $\rho$-contraction mappings involving orbits in modular function spaces. Appl. Math. Lett. 25, 1285-1290 (2012)

11. Mongkolkeha, C, Sintunavarat, W, Kumam, P: Fixed point theorems for contraction mappings in modular metric spaces. Fixed Point Theory Appl. 2011, 93 (2011). (Fixed Point Theory Appl. 2012, 103 (2012))

12. Sintunavarat, $W$, Kumam, $P$ : Weak condition for generalized multivalued $(f, \alpha, \beta)$-weak contraction mappings. Appl. Math. Lett. 24, 460-465 (2011)

13. Sintunavarat, W, Kumam, P: Gregus type fixed points for a tangential multi-valued mappings satisfying contractive conditions of integral type. J. Inequal. Appl. 2011, 3 (2011)

14. Sintunavarat, W, Kumam, P: Common fixed point theorems for hybrid generalized multi-valued contraction mappings. Appl. Math. Lett. 25, 52-57 (2012)

15. Sintunavarat, W, Kumam, $\mathrm{P}$ : Common fixed point theorems for generalized $\mathcal{J} \mathcal{H}$-operator classes and invariant approximations. J. Inequal. Appl. 2011,67 (2011)

16. Sintunavarat, W, Kumam, P: Common fixed point theorem for cyclic generalized multi-valued contraction mappings. Appl. Math. Lett. 25(11), 1849-1855 (2012)

17. Sintunavarat, W, Kumam, P: Generalized common fixed point theorems in complex valued metric spaces and applications. J. Inequal. Appl. 2012, 84 (2012)

18. Ran, ACM, Reurings, MCB: A fixed point theorem in partially ordered sets and some applications to matrix equations. Proc. Am. Math. Soc. 132, 1435-1443 (2004)

19. Nieto, JJ, Lopez, RR: Existence and uniqueness of fixed point in partially ordered sets and applications to ordinary differential equations. Acta Math. Sin. Engl. Ser. 12, 2205-2212 (2007)

20. Bhaskar, TG, Lakshmikantham, V: Fixed point theorems in partially ordered metric spaces and applications. Nonlinear Anal. 65, 1379-1393 (2006)

21. Harjani, J, López, B, Sadarangani, K: Fixed point theorems for mixed monotone operators and applications to integral equations. Nonlinear Anal. 74, 1749-1760 (2011)

22. Luong, NV, Thuan, NX: Coupled fixed points in partially ordered metric spaces and application. Nonlinear Anal. 74 983-992 (2011)

23. Luong, NV, Thuan, NX: Coupled fixed point theorems for mixed monotone mappings and an application to integral equations. Comput. Math. Appl., (2011). doi:10.1016/j.camwa.2011.10.011

24. Caballero, J, Harjani, J, Sadarangani, K: Positive solutions for a class of singular fractional boundary value problems. Comput. Math. Appl. 62(3), 1325-1332 (2011)

25. Jleli, M, Samet, B: On positive solutions for a class of singular nonlinear fractional differential equations. Bound. Value Probl. 2012, 73 (2012)

26. Abbas, M, Khan, AR, Nazir, T: Coupled common fixed point results in two generalized metric spaces. Appl. Math Comput. 217, 6328-6336 (2011)

27. Abbas, M, Sintunavarat, W, Kumam, P: Coupled fixed point in partially ordered G-metric spaces. Fixed Point Theory Appl. 2012, 31 (2012)

28. Đorić, D, Kadelburg, Z, Radenović, S: Coupled fixed point results for mappings without mixed monotone property. Appl. Math. Lett., (2012). doi:10.1016/j.aml.2012.02.022

29. Golubović, Z, Kadelburg, Z, Radenović, S: Coupled coincidence points of mappings in ordered partial metric spaces. Abstr. Appl. Anal. 2012, Article ID 192581 (2012)

30. Gordji, ME, Cho, YJ, Baghani, H: Coupled fixed point theorems for contractions in intuitionistic fuzzy normed spaces. Math. Comput. Model. 54, 1897-1906 (2011)

31. Kadelburg, Z, Radenović, S: Coupled fixed point results under tvs-cone metric and $w$-cone-distance. Advanced Fixed Point Theory 2, 29-46 (2012)

32. Sintunavarat, W, Cho, YJ, Kumam, P: Coupled coincidence point theorems for contractions without commutative condition in intuitionistic fuzzy normed spaces. Fixed Point Theory Appl. 2011, 81 (2011)

33. Sintunavarat, W, Kumam, P: Coupled best proximity point theorem in metric spaces. Fixed Point Theory Appl. 2012 93 (2012) 
34. Huang, LG, Zhang, X: Cone metric spaces and fixed point theorems of contractive mappings. J. Math. Anal. Appl. 332, 1468-1476 (2007)

35. Cho, YJ, Saadati, R, Wang, S: Common fixed point theorems on generalized distance in ordered cone metric spaces. Comput. Math. Appl. 61, 1254-1260 (2011)

36. Kada, O, Suzuki, T, Takahashi, W: Nonconvex minimization and fixed point theorems in complete metric spaces. Math. Jpn. 44, 381-391 (1996)

37. Sintunavarat, W, Cho, YJ, Kumam, P: Common fixed point theorems for c-distance in ordered cone metric spaces. Comput. Math. Appl. 62, 1969-1978 (2011)

38. Kaewkhao, A, Sintunavarat, W, Kumam, P: Common fixed point theorems of c-distance on cone metric spaces. J. Nonlinear Anal. Appl. 2012, Article ID jnaa-00137 (2012)

39. Cho, YJ, Kadelburg, Z, Saadati, R, Shatanawi, W: Coupled fixed point theorems under weak contractions. Discrete Dyn. Nat. Soc. 2012, Article ID 184534 (2012)

40. Sintunavarat, W, Cho, YJ, Kumam, P: Coupled fixed point theorems for weak contraction mapping under F-invariant set. Abstr. Appl. Anal. 2012, Article ID 324874 (2012)

doi:10.1186/1687-1812-2012-194

Cite this article as: Karapinar et al.: Coupled fixed point theorems in cone metric spaces with a c-distance and applications. Fixed Point Theory and Applications 2012 2012:194.

\section{Submit your manuscript to a SpringerOpen ${ }^{\circ}$ journal and benefit from:}

- Convenient online submission

- Rigorous peer review

- Immediate publication on acceptance

- Open access: articles freely available online

- High visibility within the field

- Retaining the copyright to your article 